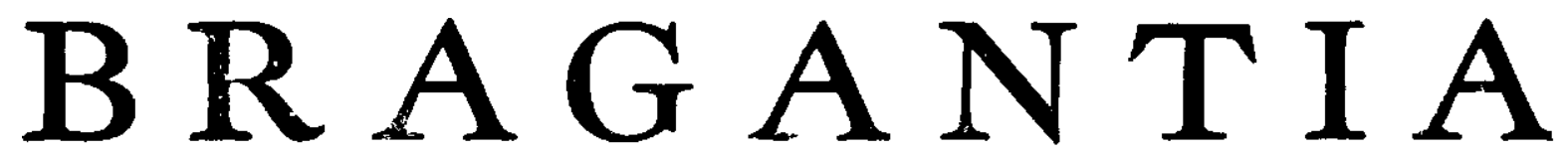

Boletim Técnico da Divisão de Experimentação e Pesquisas INSTITUTO AGRONÔMICO

\begin{tabular}{lll}
\hline \hline Vol. 10 & Campinas, Maio de 1950 & N. \\
\hline \hline
\end{tabular}

\title{
EFEITO DA ÉPOCA DE SEMEAÇĀO NA PRODUÇÃO DO HIBISCUS CANNABINUS L.
}

\author{
J. C. Medina
}

Engenheiro agrônomo, Secção de Plantas Fibrosas Diversas, Instituto Agronômico de Campinas

\section{1 - INTRODLÇÃO}

A Papoula de São Francisco (Hibiscus cannabinus L.) é uma planta herbácea, amplamente disseminada pelas regiões tropicais e subtropicais, que, periòdicamente, tem despertado interêsse como fonte de fibra libcriana macia similar à juta indiana. Já foi amplamente cultivada na India, e, em certa época, a cultura do "patsan", "ambari" ou "mestapat", como é ali denominada, teve maior importância que a própria juta, fornecendo a fibra conhecida pelas designações de "Deccan Hemp", "Ambari Hemp", "Gambo Hemp" ou "Bimlipatan Hemp". Na Rússia, tanto a planta como a fibra, conhecidas pela denominação de "kenaf", foram amplamente estudadas, seja em relação às exigências culturais da planta, seja cm relação aos processos de extração e industrializaşão da fibra. Também já foi cultivada em Java, em certa extensão, c a fibra, conhccida pelo nome de "Juta de Java", era empregada na manufatura de sacaria para açúcar. Atualmente, está sendo cultivada em pequena escala na África Oriental Francesa, onde é conhecida pela denominação de "dah".

Durante a última guerra mundial, na expectativa de privação dos suprimentos de juta indiana, a planta do "kenaf", como é agora mais conhecida nas Américas, recebeu particular atenção nas investigações realizadas no hemisfério ocidental, com o objetivo de determinar a praticabilidade da produção de fibras congêneres à juta, principalmente na América Central. $\Lambda$ produção do "kenaf" foi encorajada mediante contratos firmados entre os produtores e o "Board of Economic Welfare", do govêrno dos Estados Unidos da América do Norte. Nessa ocasião, o "kenaf" foi introduzido em Cuba, como planta produtora de fibra substituta da juta na manufatura de sacaria para açúcar, estabelecendo-se, entre o govêrno Cubano e o "U.S. Inter-Departmental Committee", um amplo plano de experimentação para determinar as possibilidades da produȩão dessa fibra.

No Brasil, e especialmente no Estado de São Paulo, o H. cannabinus, conhecido pelas denominaçôes vulgares de "Papoula de São Francisco", "Cânhamo Brasileiro" ou "Cânhamo Perini", já foi objeto de alguma experimentação nos primórdios das atividades do Instituto Agronômico de Campinas. Até 
há pouco tempo foi cultivado em pequena escala, na região do vale do Rio Paraíba, tendo sido a fibra trabalhada com sucesso nas indústrias de aniagens, que normalmente consomem a juta indiana como matéria-prima.

Apesar das várias tentativas de implantação, no Estado de São Paulo, da cultura dessa malvácea e de outras espécies produtoras de fibras similares à juta, a exploração agrícola dêsses "sucedâneos" não prosperou em nosso meio. Também nenhuma pesquisa séria sôbre os vários problemas relacionados com a sua produção econômica, desde os processos culturais até a extração mecânica e industrialização da fibra, jamais foi empreendida, desconhecendo-se mesmo o comportamento e exigências das diversas espécies fibrosas liberianas nas diferentes regiões e tipos de solo que ocorrem no Estado. Dai o fracasso das tentativas isoladas de alguns pioneiros.

Diante dessa lacuna de dados experimentais básicos para a implantação no Estado dessa atividade agrícola, a Seç̧ão de Plantas Fibrosas Diversas estabeleceu, como medida preliminar, um amplo plano de pesquisas para determinar o comportamento e produção, em diferentes regiões e tipos de solo do planalto paulista, daquelas espécies fibrosas liberianas mais em evidência, inclusive a própria juta. Instalou-se, assim, no ano agrícola 1947/48, uma série de experimentos comparativos de produção com $H$. cannabinus L., Urena lobata L. (guaxima), Crotalaria juncea L. e Corchorus olitorius L. (juta), em quatro épocas de semeação, abrangendo onze Estações Experimentais do Instituto Agronômico de Campinas.

Essa investigação foi continuada em 1948/49 e 1949/50, tendo-se considerado êste último ano agrícola como a etapa final da pesquisa. O presente trabalho tem por objetivo apresentar os resultados obtidos com o $H$. cannabinus durante êsse triênio de experimentação. Embora tôdas as espécies estudadas estivessem incluídas no mesmo experimento, em blocos ao acaso de parcelas subdivididas, as produções de cada uma delas serão analisadas separadamente, visto tratar-se de plantas de espécies e mesmo famílias botânicas diferentes. Em próximos artigos serão apresentados os resultados obtidos com as demais espécies.

\section{2 - MATERIAL E METODOS}

As sementes de $H$. cannabinus utilizadas na instalação dos experimentos provieram de um lote de sementes fornecido pela direção da Estação Experimental Central, em 1940, a qual desconhecia a sua origem.

Os experimentos foram instalados em blocos ao acaso com quatro parcelas, repetidos quatro vêzes. Cada parcela, subdividida em quatro subparcelas, foi semeada com uma das espécies fibrosas em competição, de acôrdo com as seguintes épocas de semeação :

\begin{tabular}{|c|c|}
\hline $\begin{array}{l}\text { EPOCA } \\
\text { Primeira } \\
\text { Segunda. } \\
\text { Terceira. } \\
\text { Quarta.. }\end{array}$ & $\begin{array}{l}\text { Data da semeação } \\
.15 \text { de outubro } \\
. \quad 30 " \text { " novembro } \\
. \quad 15 " \text { novem }\end{array}$ \\
\hline
\end{tabular}

Nos experimentos de 1947/48, cada subparcela compreendia doze fileiras de plantas (dez fileiras úteis e duas marginais), distanciadas, entre si, 20 centímetros. No caso do $H$. cannabinus, a semeação foi feita em linha 
corrida, na base de 1 grama de sementes por metro linear, correspondendo a 50 quilos de sementes por hectare. Fintretanto, nos experimentos de $1948 / 49$ e 1949/50, as distâncias entre fileiras foram aumentadas para 30 centímetros, a fïm de facilitar as operaçōes de capina, mantendo-se a mesma base de semeação de 1 grama de sementes por metro linear, correspondendo agora a 33 quilos de sementes por hectare. Para conservar a mesma árca das subparcelas, isto é, $10 \mathrm{~m}^{2}$, o número de fileiras nestes dois últimos anos agrícolas foi reduzido para dez, sendo oito fileiras úteis e duas marginais.

O preparo do terreno foi executado da maneira usual, não se aplicando, em nenhum dos anos agrícolas, qualquer adubação nos experimentos.

Devido à falta de meios para efetuar a maceração dos caules das plantas colhidas, a presente investigação restringiu-se à determinação da produção de massa verde para cada época de semeação. Os dados de "produção provável" de fibra, citados neste trabalho, baseiam-se $\mathrm{cm}$ resultados obtidos em um cnsaio preliminar de maceração, realizado em 1944, no qual se obtiveram, para o $H$. cannabinus, em média, $4,2 \%$ de fibras sôbre caules verdes enfolhados. Devido, também, à ausência de dados concretos sôbre a época de corte dos caules, sob as nossas condições, adotou-se, como regra, colhêr os caules durante a fasc de pleno florescimento das plantas.

\section{3 - RESULTADOS}

\section{1 - ANO AGRÍCOLA $1947 / 48$}

Neste ano agrícola foram instalados onze experimentos, distribuídos nas localidades indicadas no quadro 1.

Qunano 1.--Produção méclia de massa verde de $I I$. cannabinus, em quilos por subparcela de $10 \mathrm{~m}^{2}$, em cada époea de semeação e localidade, nos experimentos do ano agrícola 1947/48. Médias de 4 repetições

\begin{tabular}{|c|c|c|c|c|c|c|}
\hline \multirow{2}{*}{ Localidiales } & \multicolumn{4}{|c|}{ Produção de massa verde nas épocas } & \multirow{2}{*}{$\begin{array}{c}\text { "F"' } \\
\text { parat } \\
\text { ćpocas }\end{array}$} & \multirow{2}{*}{$\begin{array}{c}\text { Diferença } \\
\text { mínima } \\
\text { significa- } \\
\text { tiva } \\
(\mathrm{P}=0,05)\end{array}$} \\
\hline & l'rimeira & Segunda & Terceina & Q larta & & \\
\hline & $\mathrm{kg}$ & $k g$ & $k q$ & $k g$ & & $k g$ \\
\hline Pindorama & 69,2 & 69,3 & 53.4 & 36,2 & $6,49 *$ & \pm 9.9 \\
\hline Mococa ....... & 48,3 & 49,0 & 26,9 & 17,7 & $25,78 * *$ & $\pm 4,9$ \\
\hline Ribeirão Prêto & 46,2 & 57,3 & 48,7 & 39.9 & 2,20 n.s. & - - - - \\
\hline Capão Bonito & 62,3 & 64,4 & 52,2 & 49,9 & $0,02 *$ & $\pm 4,7$ \\
\hline Tatuí ....... & 56,4 & 56,6 & 44,4 & $37, \overline{3}$ & $18,16^{* *}$ & $\pm 3, \bar{i}$ \\
\hline Limeira . . . . . & 24,2 & 26,6 & 22,0 & 18.6 & 0,53 n.s. & - \\
\hline Santa Rita & 23,5 & 17,2 & 9,0 & 5,2 & $44,61 * *$ & $\pm 1,9$ \\
\hline Jaú $\ldots \ldots$. & 18,8 & 17,2 & 13.5 & 8,5 & 3,44 n.s. & - \\
\hline Campinus... & 28,4 & 27,3 & 24,4 & 11,9 & $11,08 * *$ & \pm 4.9 \\
\hline 'Tietề ..... & 36,7 & 36,2 & 34,5 & 24.7 & $5,14 *$ & \pm 4.0 \\
\hline Tupi & 20,2 & 29,6 & 17,2 & 7,9 & $13,58 * *$ & $\pm 3,9$ \\
\hline
\end{tabular}

$*$ = significativo $(5 \%)^{* *}=$ altamente significativo. 
No experimento localizado $\mathrm{cm}$ Campinas, as plantas de uma das repetições foram totalmente destruídas por saúvas, ao passo que, em Ribeirão P'êto, ocorreu um ataque generalizado de nematóides. Devido ao atraso no preparo da terra, a primeira época de semeação dos experimentos de Mococa e Limeira foi transferida para 20 c 30 de outubro, respectivamente, conservando-se, porém, o mesmo intervalo de 15 dias entre as demais épocas de semeação.

No quadro l encontram-ic os dados médios de produção de massa verde, em quilos, em cada época de scmeação e localidade, assim como a indicação do efeito das diferentes épocas de semeação sôbre a produção de massa verde e os valores da diferença mínima significativa para $\mathrm{P}=0,05$.

Os dados do quadro 1 mostram que, em cinco localidades - Mococa, Tatuí, Santa Rita, Campinas e Tupi -.. o efeito das épocas de semeação sôbre a produção de massa verde foi altamente significativo. Fm três outras locialidades - Pindorama, Capão Bonito e Tietê - o efeito já foi apenas significativo, ao passo que, em libeirão l'rêto, limeira e Jaú, não houve diferença significativa de produção devido à época de semeação.

De modo geral, as produções das duas primeiras épocas de semeação, correspondendo a 15 e 30 de outubro, respectivamente, se equivaleram; geralmente, porém, foram superiores às produções das épocas mais tardias, principalmente em relação à de 30 de novembro.

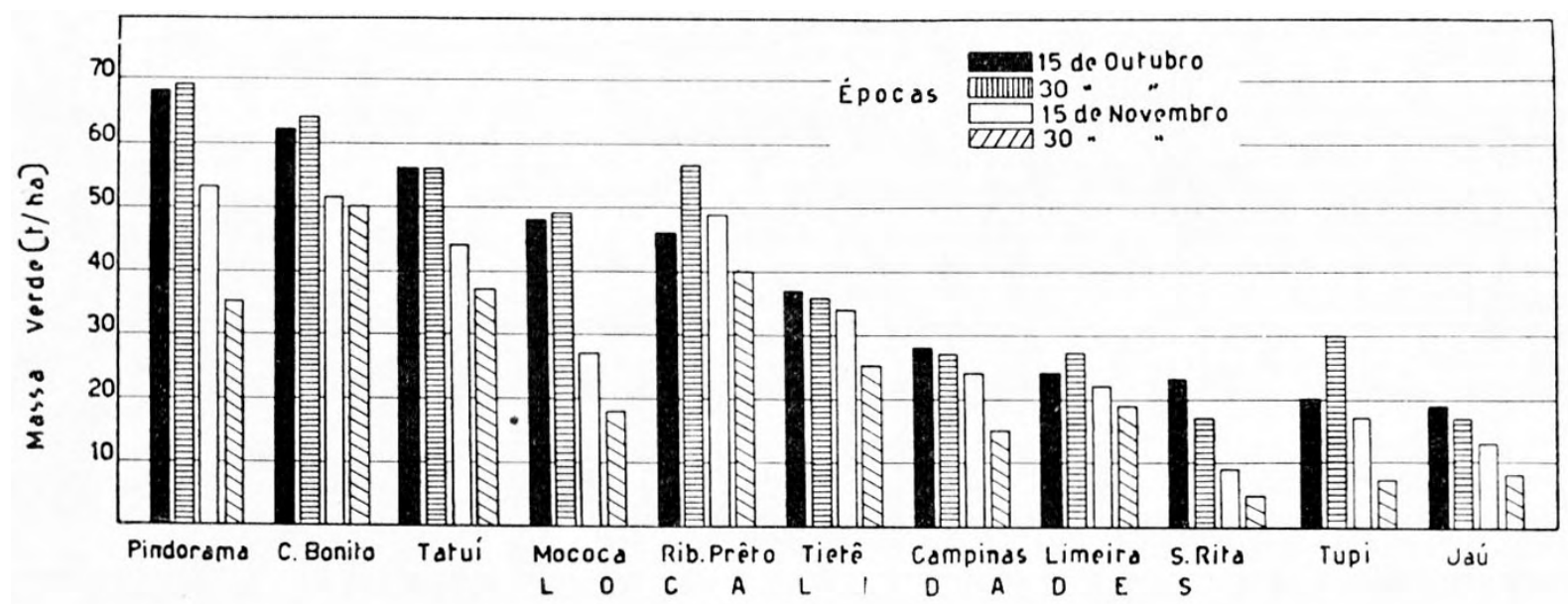

Figura 1.-Produções médias de massa verde do $H$. cannabinus, em toneladas por hectare, em cada época de semeação e localidade, no ano agrícola 1947/48.

Na figura l estão representadas as produções cm cada época de semcaşão e localidade, em toneladas por hectare. Nota-se que as produçoes corrospondentes a Pindorama, Capão Bonito, Tatuí, Mococa e Ribcirão Prêto, principalmente aquelas das duas primeiras localidades, foram bastante satisfatórias.

\section{$3.2-$ ANO AGRÍlCOLA $19+48 / 49$}

Em continuação com a pesquisa para determinar o efeito da época de semeação sôbre a produção de inassa verde do $H$. cannabinus, foram insta- 
lados, no ano agrícola 1948/49, mais onze experimentos de ćpocas de semeação, nas mesmas localidades, referentes ao ano agrícola anterior.

Durante a execução dos experimentos dêste ano agrícola, não houve nenhuma ocorrência a relatar, a não scr que, nos experimentos de Jaú e Limeira, a colheita dos caules foi realizada quando as plantas já apresentavam os frutos completamente maduros.

No quadro 2 estão indicadas as produções médias de massa verde, em quilos, em cada época de semeaceão e localidade, assim como o efeito das diferentes épocas de semeação sôbre a produção e os valores da diferença mínima significativa para $\mathrm{P}=0,05$.

Os dados do quadro 2 mostram que, no ano agrícola 1948/49, em quatro localidades - Pindorama, Mococa, Santa Rita e Tietê - o efeito das épocas de semeação sôbre a produção de caules com fôlhas foi altamente significativo. Em quatro outras localidades - Ribeirão Prêto, Capão Bonito, Tatuí e Jaú - o efeito já foi apenas significativo, e, em Limeira, Campinas e Tupi, o efeito não foi significativo.

Quadro 2.-- Produção média de massa verde de H. cannabinus, em quilos por subparcela de $10 \mathrm{~m}^{2}$, em cada época de semeação e localidade, nas experiências do ano agrícola 1948/49. Médias de 4 repetições

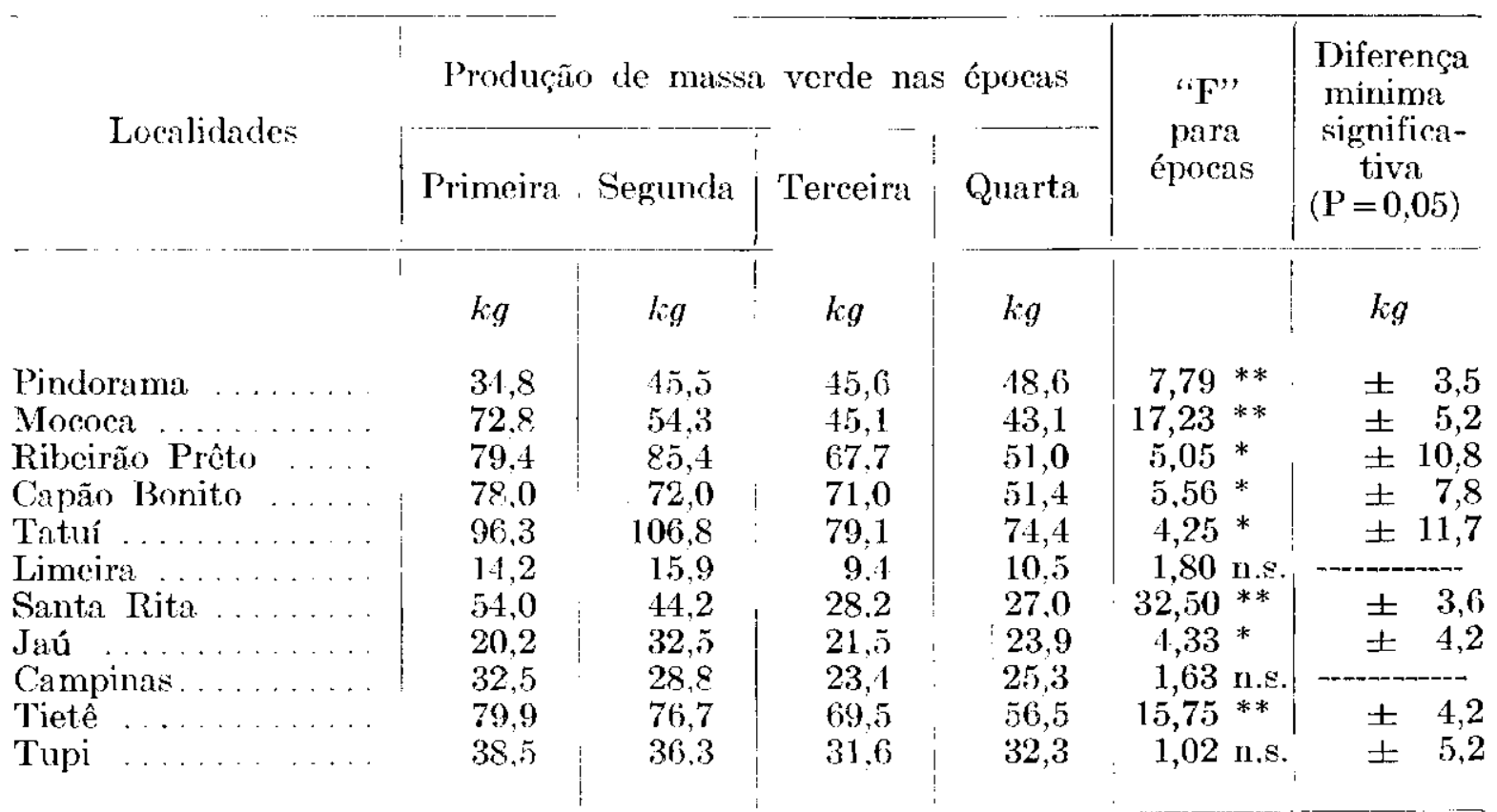

* = significativo $(5 \%) \quad * *=$ altamente significativo $(1 \%)$.

Com exceção de Pindorama e Limeira, nas demais localidades as produções nestc ano agrícola foram bem superiores àquelas do ano agrícola anterior, principalmente em Ribcirão Prêto, Tatuí, Capão Bonito, Mococa e Tietê. Novamente ficou evidente a superioridade das duas primeiras épo- 
cas de semeação, a rrespondendo a 15 e 30 de outubro, sôbre as duas épocas mais tardias, corr spondendo a 15 e 30 de novembro.

$\mathrm{Na}$ figura 2 estão representadas as produções médias de massa verde, em toneladas por hectare, em cada época de semeação e localidade experimentada.

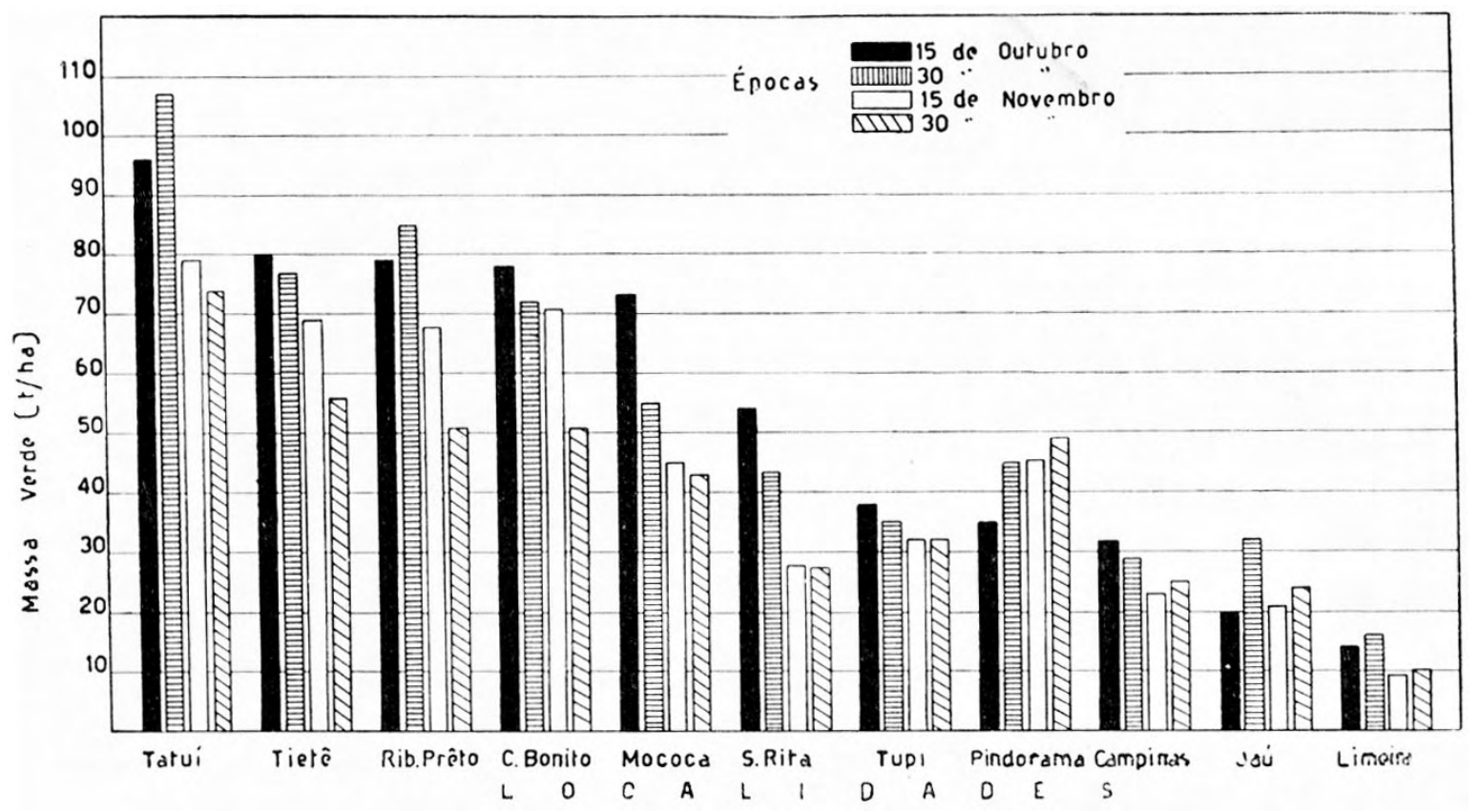

Figura 2.-Produções médias de massa verdc de $H$. camabinus, en toneladas por hectare, em cada ćpoca de semeaçāo e localidade, no ano agrícola 1948/49.

\section{3 - ANO AGRICOLA 1949/50}

Finalizando a presente pesquisa, foram instalados, durante o ano agrícola de 1949/50, mais dez experimentos, nas mesmas localidades, referentes aos anos agrícolas anteriores, tendo-se deixado de instalar, entretanto, por falta de sementes, o correspondente a Campinas.

Devido, porém, à grande irregularidade na germinação das sementes e crescimento das plantas, o experimento de Limeira foi considerado perdido, o mesmo acontecendo com uma das repetiçóes do experimento de Ribcirão Prêto.

No quadro 3 estão indicados os dados médios de produção de massa verde, cm quilos, em cada época de semeação e localidade, assim como o efeito das diferentes épocas de semeação sôbre a produção e os valores da diferença mínima significativa para $\mathrm{P}=0,05$.

Os dados do quadro 3 mostram que, no ano agrícola 1949/50, em duas localidades - Pindorama e Jaú - o efeito da época de semeação sôbre a produção de massa verde foi altamente significativo. Em três localidades 
Quadro 3.-Produção média de massa verde, em quilos, por subparcela de $10 \mathrm{~m}^{2}$, em cada época de semeação e localidade, nos experimentos do ano agrícola 1949/50. Médias de 4 repetições

\begin{tabular}{|c|c|c|c|c|c|c|}
\hline \multirow{2}{*}{ Localidades } & \multicolumn{4}{|c|}{ Produção de massa verde nas épocas } & \multirow{2}{*}{$\begin{array}{c}\text { "F" } \\
\text { para } \\
\text { épocas }\end{array}$} & \multirow{2}{*}{$\begin{array}{l}\text { Diferença } \\
\text { minima } \\
\text { significa- } \\
\quad \text { tiva } \\
(P=0,05)\end{array}$} \\
\hline & Primeira & Segunda & Terceira & Quarta & & \\
\hline & $k g$ & $k g$ & $k g$ & $k g$ & & $\operatorname{lgg}$ \\
\hline Pindorama & 78,1 & 52,6 & 56,4 & 35,9 & $67,32 * *$ & $\mathbf{3}, 3$ \\
\hline Mococa . . . . . & 41,7 & 48,7 & 40,0 & 30,4 & 1,16 n.s. & 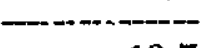 \\
\hline Ribeirão Prêto & 58,0 & 33,8 & 37,0 & 32,0 & $5,00 *$ & $\pm 10,7$ \\
\hline Capão Bonito & $67, \tilde{5}$ & 56,5 & 50,5 & 57,5 & $5,61^{*}$ & $\pm 4,7$ \\
\hline Tatuí ....... & 103,0 & 115,6 & 92,5 & 88,0 & 1,82 n.s. & 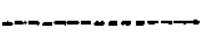 \\
\hline Santa lRita & 18,2 & 14,5 & 14,0 & 7,5 & 3,14 n.s. & 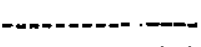 \\
\hline Jaú $\ldots \ldots$ & 73,2 & 69,9 & 69,2 & 60,4 & $4,39 * *$ & \pm \\
\hline Tietê. & 64,5 & 60,5 & 50,5 & 51,0 & $5,68 *$ & $\pm \quad 4,7$ \\
\hline Tupi . & 50,0 & 49,2 & 40,4 & 33,8 & 2,44 n.s. & \\
\hline
\end{tabular}

${ }^{*}=$ significativo $(5 \%) \quad{ }^{* *}=$ altamente signficativo $(1 \%)$.

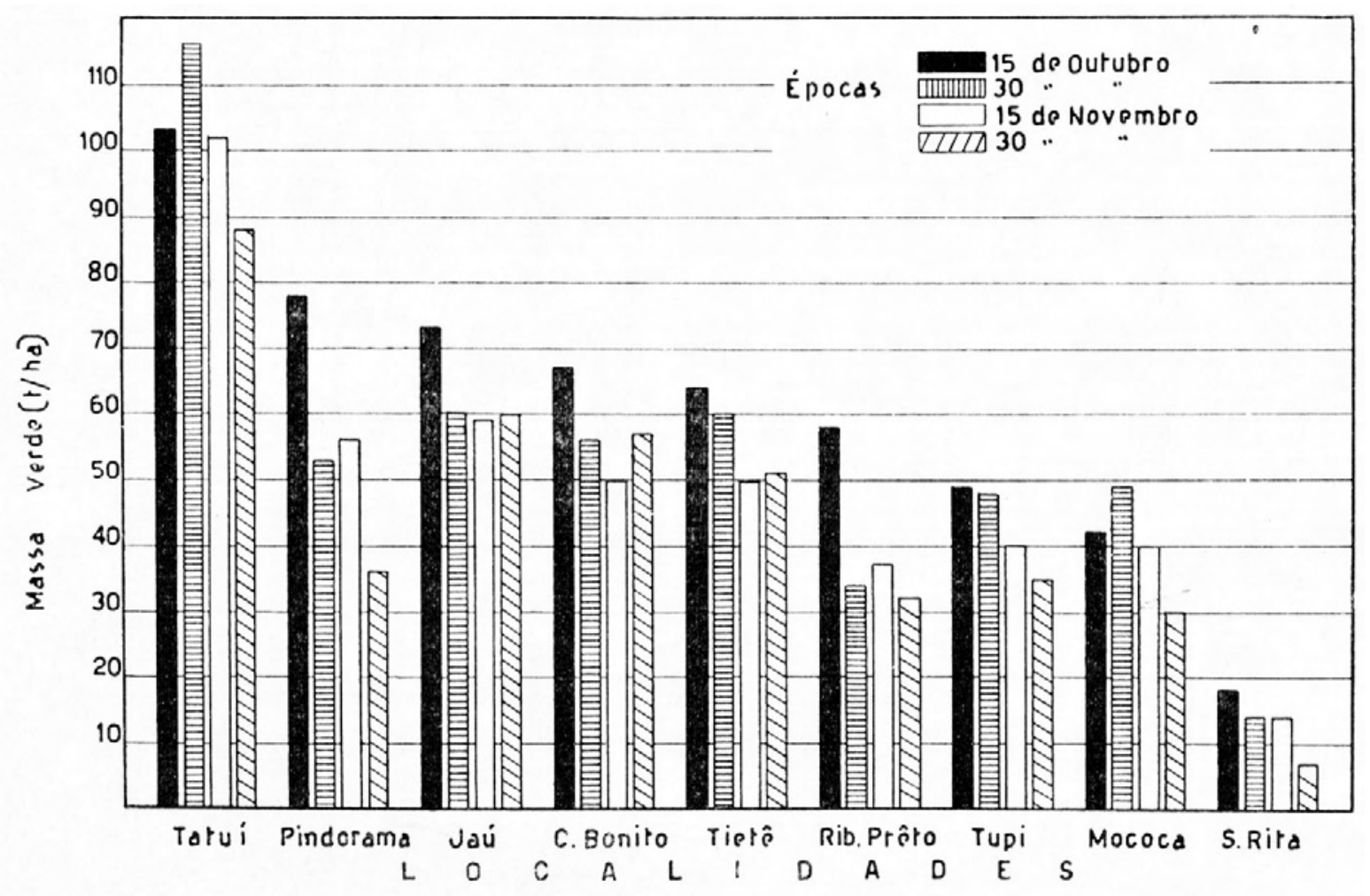

Figura 3.-Produçōes médias de massa verde do $H$. camnabinus, en toncladas por hectare, em cada época de semeação e localidade, no ano agrícola 1949/50. 
- Ribeirão Prêto, Capão Bonito e Tietê - o efeito de época de semeação sôbre a produção foi apenas significativo, ao passo que em quatro localidades - Mococa, Tatuí, Santa Rita e Tupi - não houve diferença significativa de produção entre as épocas de semeação.

Na figura 3 estão representadas as produções médias de massa verde, em toneladas por hectare, em cada época de semeação e localidade.

\section{4 - DISCUSSÃO}

Supondo a produção de massa verde da última época de semeação 30 de novembro - igual a 100, que, com raras exceções, corresponde às produções mais baixas, obteríamos para as demais épocas, em cada localidade e ano agrícola, as proporções apresentadas no quadro 4 .

Os dados do quadro 4 mostram, portanto, que, em média, nos três anos agrícolas considerados, o aumento de produção de massa verde nas três primeiras épocas de semeação, em relação àquela da última época, foi de $65 \%, 59 \%$ e $26 \%$, para a primeira, segunda e terceira épocas de semeação, respectivamente.

QUADRo 4. - Relação entre as produções médias de massa verde das três primciras ćpocas de semeação e as da ultima época, consideradas igual a 100, por localidade e ano agricola

\begin{tabular}{|c|c|c|c|c|c|c|c|c|c|}
\hline \multirow{2}{*}{$\begin{array}{l}\text { Locali-: } \\
\text { dades }\end{array}$} & \multicolumn{3}{|c|}{$1947 / 48$} & \multicolumn{3}{|c|}{$1948 / 49$} & \multicolumn{3}{|c|}{$1949 / 50$} \\
\hline & $\begin{array}{c}\text { Primeira } \\
\text { (poca }\end{array}$ & $\begin{array}{c}\text { Segunda } \\
\text { época }\end{array}$ & $\begin{array}{c}\text { Terceira } \\
\text { época }\end{array}$ & $\begin{array}{c}\text { Primeira } \\
\text { época }\end{array}$ & $\begin{array}{l}\text { Segunda } \\
\text { época }\end{array}$ & $\begin{array}{c}\text { Terceira } \\
\text { época }\end{array}$ & $\begin{array}{c}\text { Primeira } \\
\text { época }\end{array}$ & $\begin{array}{c}\text { Segunda } \\
\text { época }\end{array}$ & $\begin{array}{c}\text { Terceira } \\
\text { época }\end{array}$ \\
\hline $\begin{array}{l}\text { Pindorama } \\
\text { Mococa .. } \\
\text { R. Prêto.. } \\
\text { C. Bonito } \\
\text { Tatuí .... } \\
\text { Limeira . . } \\
\text { Sta. Rita. } \\
\text { Jaú . . . } \\
\text { Campinas } \\
\text { Tietê .... } \\
\text { Tupi ... }\end{array}$ & $\begin{array}{l}191 \\
273 \\
116 \\
125 \\
150 \\
130 \\
452 \\
221 \\
191 \\
148 \\
256\end{array}$ & $\begin{array}{l}191 \\
277 \\
146 \\
129 \\
151 \\
143 \\
331 \\
202 \\
183 \\
146 \\
375\end{array}$ & $\begin{array}{l}147 \\
152 \\
122 \\
105 \\
118 \\
118 \\
173 \\
159 \\
164 \\
140 \\
218\end{array}$ & $\begin{array}{r}72 \\
169 \\
156 \\
152 \\
129 \\
135 \\
200 \\
85 \\
128 \\
141 \\
119\end{array}$ & $\begin{array}{r}94 \\
126 \\
167 \\
140 \\
143 \\
151 \\
164 \\
136 \\
114 \\
136 \\
112\end{array}$ & $\begin{array}{r}94 \\
105 \\
133 \\
138 \\
106 \\
89 \\
104 \\
90 \\
92 \\
123 \\
98\end{array}$ & $\begin{array}{c}217 \\
137 \\
181 \\
117 \\
117 \\
243 \\
121 \\
126 \\
148\end{array}$ & $\begin{array}{r}146 \\
160 \\
106 \\
98 \\
131 \\
193 \\
116 \\
119 \\
145\end{array}$ & $\begin{array}{r}157 \\
131 \\
116 \\
88 \\
105 \\
187 \\
114 \\
99 \\
119\end{array}$ \\
\hline Média . . & 205 & 207 & 147 & 135 & 135 & 106 & 156 & 135 & 124 \\
\hline
\end{tabular}

No quadro 5 estão indicados os dados sôbre o número de dias para germinação das sementes e início de florescimento das plantas das três últimas épocas de semeação, em relação aos da primeira época, para os três anos agrícolas de experimentação.

Assim, embora as semeações tivessem sido feitas a intervalos quinzenais, e a última época de semeação fôsse feita 45 dias depois da primeira, o início de florescimento das plantas da última época de semeação, em relação às plantas da primeira época de semeação, foi, em média, apenas de $9,4,11,6$ e 11,1 dias mais tarde, nos anos agrícolas de 1947/48, 1948/49 e 1949/50, respectivamente. 
Quadro 5.- Média de dias deccrridos para germinação das sementes e início de florescimento do $H$. cannabinus da $2 .^{\mathrm{a}}, 3 .^{\mathrm{a}}$ e $4 .^{\mathrm{a}}$ épocas de semeação, em relação à $1 .^{\mathrm{a}}$ época

\begin{tabular}{|c|c|c|c|c|c|c|}
\hline \multirow{2}{*}{ Ano agrícola } & \multicolumn{3}{|c|}{$\begin{array}{l}\text { Número de dias para germinação } \\
\text { em relação à primeira época }\end{array}$} & \multicolumn{3}{|c|}{$\begin{array}{l}\text { Námero de dias para início do } \\
\text { florescimento em relaşão à pri- } \\
\text { meira época }\end{array}$} \\
\hline & $\begin{array}{c}\text { Segunda } \\
\text { época }\end{array}$ & $\begin{array}{c}\text { Terceira } \\
\text { época }\end{array}$ & $\begin{array}{c}\text { Quarta } \\
\text { época }\end{array}$ & $\begin{array}{c}\text { Segunda } \\
\text { época }\end{array}$ & $\begin{array}{c}\text { Terceira } \\
\text { época }\end{array}$ & $\begin{array}{l}\text { Quarta } \\
\text { época }\end{array}$ \\
\hline $1947 / 48\left(^{1}\right)$ & 15,2 & 31,2 & 46,1 & 3,4 & 6,9 & 9.4 \\
\hline $1948 / 49\left(^{2}\right)$ & 9,0 & 23,7 & 41,6 & 2,7 & 7,6 & 11,6 \\
\hline $1949 / 50\left(^{\circ}\right)$ & 14,8 & 28,3 & 41,4 & 3,1 & 7,7 & 11,3 \\
\hline
\end{tabular}

(1) Médias de 8 localidades. (2) Médias de 10 localidades. (3) Médias de 9 localidades.

No quadro 6 estão indicados os dados referentes à altura média das plantas, em centímetros, por ocasião da colheita, e ao número médio de dias para germinação das sementes e início de florescimento do $H$. cannabinus, nas diferentes épocas de semeação, durante os anos agrícolas de 1947/48, $1948 / 49$ e 1949/50. Isso indica que essa planta exibe uma marcante reação à duração do dia (fotoperiodismo).

Quadro 6.-Altura média das plantas, em centímetros, por ocasião do corte, e número médio de dias decorridos entre a germinação e ińcio de florescimento do $H$. cannabinus, em diferentes épocas de semeação, durante os anos agrícolas de 1947/48, $1948 / 49$ e $1949 / 50$

\begin{tabular}{|c|c|c|c|}
\hline Ano agrícola & Época de semeação & $\begin{array}{l}\text { Altura média das } \\
\text { plantas }\end{array}$ & $\begin{array}{l}\text { Média de dias entre } \\
\text { germinação e início } \\
\text { de florescimento }\end{array}$ \\
\hline & & $\mathrm{cm}$ & número \\
\hline \multirow[t]{3}{*}{$1947 / 48$} & 15 outubro & $202^{*}$ & $149,6 * *$ \\
\hline & 30 outubro & $200^{*}$ & $137,9^{* *}$ \\
\hline & 15 novembro & $183^{*}$ & $125,4^{* *}$ \\
\hline \multirow{4}{*}{1948,49} & & & \\
\hline & 15 outubro & $232^{*}$ & $139,2^{* * *}$ \\
\hline & 30 outubro & $218^{*}$ & $133,9^{* * * *}$ \\
\hline & $\begin{array}{l}15 \text { novembro } \\
30 \text { noyembro }\end{array}$ & $208^{*}$ & $123,1 * * *$ \\
\hline \multirow{5}{*}{$1949 / 50$} & & & \\
\hline & 15 outubro & $198 * *$ & $143,5^{*}$ \\
\hline & 30 outubro & $183^{* *}$ & $131,9^{*}$ \\
\hline & 15 novembro & $176^{* *}$ & $122,9^{*}$ \\
\hline & 30 novembro & $164^{k *}$ & $113,8^{*}$ \\
\hline
\end{tabular}

* = médias de 9 localidades ${ }^{* *}=$ médias de 8 localidades ${ }^{* *}=$ médias de 10 localidades. 
Os dados do quadro 6 mostram que, quanto mais tardia a época de semeação, tanto menor era a altura média das plantas, assim como a duração de seu ciclo vegetativo. Em consequência, a produção de massa verde vai decrescendo da primeira para a última época de semeação. $\mathrm{O}$ exame dos registos de chuvas nas diferentes localidades experimentadas mostrou que não havia nenhuma relação entre as produções das diferentes épocas de semeação e as precipitações pluviométricas ocorridas durante a semeação e florescimento das plantas.

Analisando, conjuntamente, para cada localidade, as produções obtidas no triênio agrícola $1947 / 50$, obtivemos os " $F$ " calculados para os efeitos ano, época e a interação ano x época, indicados no quadro 7 .

Os dados do quadro 7 mostram que o efeito anos foi altamente significativo, isto é, ocorreu grande variação na produção devida a anos, o mesmo acontecendo em relação ao efeito épocas de semeação. Em duas localidades, Pindorama e Santa Rita, a interação ano x época de semeação foi altamente significativa, isto 6 , houve um comportamento diferencial das épocas nos diferentes anos agrícolas, ao passo que em duas localidades -- Capão Bonito e Jaú - o comportamento diferencial das épocas de semeação foi menos acentuado, isto é, apenas significativo a $5 \%$. Finalmente, em quatro localidades - Mococa, Tatuí, Tietê e Tupi - as épocas de semeação mantiveram-se estáveis nos anos agrícolas considerados.

Quadro 7.-Resultados do "F" calculado para os efeitos anos e épocas de semeação, assim como para a interação ano $\mathrm{x}$ época, da análise de produções do triênio agrícola $1947 / 50$, por localidade

\begin{tabular}{|c|c|c|c|}
\hline \multirow[b]{2}{*}{ Inocalidade } & \multicolumn{3}{|c|}{ "F"' calculado } \\
\hline & Ano & Fipoca & $\begin{array}{l}\text { Interação } \\
\text { ano } \mathrm{x} \text { época }\end{array}$ \\
\hline 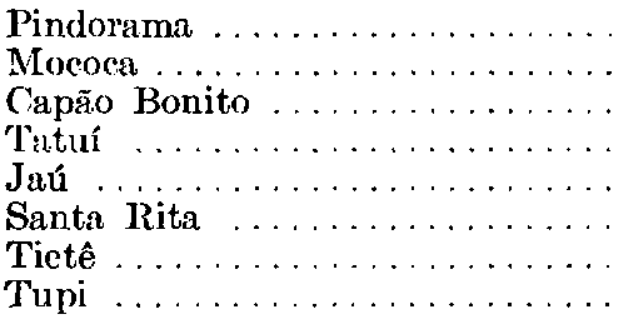 & $\begin{array}{r}13,88^{* *} \\
15,68^{* *} \\
10,69^{* *} \\
61,57^{* *} \\
561,95^{* *} \\
186,54^{* *} \\
200,63^{* *} \\
45,74^{* *}\end{array}$ & $\begin{array}{r}14,43^{* *} \\
16,25^{* *} \\
11,08^{* *} \\
9,26^{* *} \\
7,54^{* *} \\
48,11^{* *} \\
22,06^{* *} \\
8,63^{* *}\end{array}$ & $\begin{array}{l}11,36^{* *} \\
2,38 \\
2,96^{*} \\
0,31 \\
3,23^{*} \\
5,42^{* *} \\
2,06 \\
1,22\end{array}$ \\
\hline
\end{tabular}

${ }^{*}=$ significativo $(5 \%)^{* *}=$ altamente significativo $(1 \%)$.

Finalmente, supondo apenas as produções obtidas na primeira época de semeação, que foi, em geral, a melhor época, e uma percentagem de "fibra provável" de $4,2 \%$ sôbre caules verdes enfolhados, obteríamos, em média, no triênio agrícola $1947 / 50$, por Iocalidade, as produções prováveis de massa verde e fibra, em quilos por hectare, indicadas no quadro 8. 
Quadro 8.-Produção média de massa verde e "fibra provável", em quilos por hectare, para o triênio agrícola $1947 / 50$ e por localidade, na primeira época de semeação (15 de outubro)

\begin{tabular}{|c|c|c|}
\hline Localidade & $\begin{array}{c}\text { Produção de massa } \\
\text { verde }\end{array}$ & $\begin{array}{c}\text { "Produção provável" } \\
\text { de fibra }\end{array}$ \\
\hline & $k g$ & $k g$ \\
\hline Pindorama & 60700 & 2549 \\
\hline Mococa ....... & 54266 & 2279 \\
\hline Ribeirāo Prêto . . . & 61200 & 2570 \\
\hline Capão Bonito . . & 69266 & 2909 \\
\hline Tatuí......... & 85233 & 3580 \\
\hline Santa Rita ... & 31900 & 1340 \\
\hline$\ldots \ldots \ldots \ldots$ & 37400 & 1571 \\
\hline$\ldots \ldots \ldots \ldots \ldots \ldots \ldots \ldots$ & 63266 & 2657 \\
\hline Tupi ... & 36233 & 1522 \\
\hline
\end{tabular}

As experiências aqui relatadas foram conduzidas em diversas localidades representativas dos diferentes tipos de solo do Estado, desde os mais férteis, como a terra roxa legítima, até os do glacial e arenito de Botucatu, que $\mathrm{s}$ ão os mais pobres. $\mathbf{E}$ interessante observar que justamente nas localidades com solos de formação glacial, como ocorre em Tatuí, Capão Bonito e Tietê, é que foram obtidas, em média, as produções de massa verde mais elevadas, como mostram os dados do quadro 8. Convém salientar, entretanto, que as produções indicadas neste quadro não devem ser interpretadas como representativas de produções a serem esperadas na grande cultura, mas apenas como indicativas de "produção provável", apesar de não terem sido aqui considerados outros fatôres que podem intervir na produção, como densidade de semeação, espaçamento, adubação, etc. $O$ valor de qualquer fibra nova é frequentemente computado em relação ao valor das fibras com que competirá em um determinado campo industrial. De fato, na produção de uma fibra equivalente à juta indiana, por exemplo, não basta que apresente boas qualidades têxteis e em condições de ser utilizada na indústria de aniagens : é preciso, antes, que a sua produção seja econômica, de modo que concorra vantajosamente com a similar importada, sem necessidade de medidas protecionistas.

A grande procura no Estado está dirigida para fibras de baixo valor, que são manufaturadas em artigos também de baixo valor. Isso significa que seria difícil de se conseguir aqui, considerando o elevado custo de mão de obra, a produção barata de fibras próprias para consumo na indústria de aniagens, através do oneroso processo da maceração.

A praticabilidade da produção do "kenaf", como substituto da juta, apenas seria viável no caso de essa fibra poder ser comercializada aos preçosteto da juta ou algo inferiores, com margem satisfatória de lucro aos produtores. As propriedades dessa fibra não são suficientemente diferentes, de 
modo que justifiquem maiores preços para ser industrializada em artigos que normalmente são manufaturados com a juta.

O problema da extração da fibra do "kenaf" poderia constituir o maior óbice à produção econômica da cultura no Estado. $\mathrm{O}$ tradicional processo de maceração empregado na Índia, para extração da fibra da juta, não seria aqui econômico, pois os nossos salários são relativamente elevados e a mão de obra é relativamente escassa.

Felizmente, porém, a cultura do "kenaf" poderá ser feita totalmente por meios mecânicos, desde a semeação até o corte dos caules, e, o que é mais importante, êstes também podem ser desfibrados mecânicamente. Dêsse modo, a fibra do "kenaf" poderá agora competir vantajosamente com a juta indiana, uma cultura que na Îndia é quase totalmente realizada por trabalho manual.

Em Cuba, o "kenaf" é atualmente semeado mecânicamente, por meio de semeadeiras semelhantes às de arroz e outros cereais, e a colheita dos caules executada com ceifadeiras de cânhamo, adaptadas. Para a desfibragem estão empregando com sucesso as desfibradeiras automáticas de henequém, sendo os feixes de caules transportados diretamente da cultura para o galpão de desfibragem. Estas máquinas retiram, por meio de raspagem, o lenho e resíduos vegetais, deixando a fibra limpa que, em seguida, é secada ao sol. A capacidade destas máquinas é estimada em cêrca de 7 toneladas de fibra sêcas por 10 horas de serviço. Na base de $4 \%$ de fibras sêcas sôbre caules verdes enfolhados, isso equivaleria à desfibragem de 175 toneladas diárias de massa verde, correspondente à produção de cêrca de 4 hectares plantados com "kenaf".

Com base, portanto, nos dados experimentais relatados neste trabalho e nas informações sôbre a desfibragem mecânica do "kenaf", executada com sucesso em Cuba, justifica-se plenamente o amparo oficial no estabelecimento e desenvolvimento da cultura desta malvácea no Estado, como uma fonte doméstica de fibra similar à juta indiana, própria para ser industrializada sem qualquer entrave nas cardas da nossa indústria de aniagens.

\section{SUMMARY}

In order to determine the effect of planting time on growth and yield of kenaf (Hibiscus cannabinus L.), experimental trials in randomized blocks were conducted on various soils in different localities of the State of São Paulo, during the crop years 1947-48, 1948-49, and 1949-50.

Plantings were made at 15 day intervals, beginning Octobre 15 , and ending November 30 , in rows $20 \mathrm{~cm}$ appart and seeded at the rate of 50 kilograms of seed per hectare in the 1947.48 plantings, and in rows $30 \mathrm{~cm}$ appart and seeded at the rate of 33 kilograms of seed per hectare in the 1948-49 and 1949-50 plantings.

Harvest operations were carried out at the time the plants were in full bloom and green weight of foliated stems were determined.

Average yield data showed that higher yields of green foliated stems were obtained from plantings made on October 15 and October 30 . The data on average height attained by the plants for each date of plantings tested show a decrease from the first (Oct. 15) to the last (Nov. 30) plantings. 
It was found that in spite of the fact that the last planting were made 45 days after the first planting, there was a difference of only 11 days in the time of opening of the first flower. This is due to the fact that kenaf exhibits a marked response to length of day (photoperiodism).

The results obtained in this investigation showed that kenaf is a fibrous bast plant well adapted to cultivation on various soils types and in different locations in the State of São Paulo.

Experience in Cuba indicates that production of kenaf can be mechanized both in the field and decorticating operations. This possibility of mechanization plus the indication of substancial yields indicated by the present tests, fully justifies official encouragement for further study and development of this plant as a domestic source of jutelike fiber that might be used in coffee bag manufacture. 